\title{
Focal mechanism determinations of earthquakes along the North Anatolian fault, beneath the Sea of Marmara and the Aegean Sea
}

\author{
Masaru Nakano ${ }^{1 *}$, Seckin Citak ${ }^{1}$ and Doğan Kalafat ${ }^{2}$
}

\begin{abstract}
We determined the centroid moment tensor (CMT) solutions of earthquakes that occurred along the North Anatolian fault (NAF) beneath the Sea of Marmara and the Aegean Sea, using data obtained from Turkey's broadband seismograph network. The CMT solution of the 2014 Aegean Sea earthquake (Mw 6.9) represents a strike-slip fault, consistent with the geometry of the NAF, and the source-time function indicates that this event comprised several distinct subevents. Each subevent is considered to have ruptured a different fault segment. This observation indicates the existence of a mechanical barrier, namely a NAF segment boundary, at the hypocenter. CMT solutions of background seismicity beneath the Aegean Sea represent strike-slip or normal faulting along the NAF or its branch faults. The tensional axes of these events are oriented northeast-southwest, indicating a transtensional tectonic regime. Beneath the Sea of Marmara, the CMT solutions represent mostly strike-slip faulting, consistent with the motion of the NAF, but we identified a normal fault event with a tensional axis parallel to the strike of the NAF. This mechanism indicates that a pull-apart basin, marking a segment boundary of the NAF, is developing there. Because ruptures of a fault system and large earthquake magnitudes are strongly controlled by the fault system geometry and fault length, mapping fault segments along NAF can help to improve the accuracy of scenarios developed for future disastrous earthquakes in the Marmara region.
\end{abstract}

Keywords: Centroid moment tensor; Strike-slip fault system; Fault segment boundary; SWIFT system

\section{Background}

The North Anatolian fault (NAF) is a strike-slip fault system running from east to west in northern Turkey that forms the boundary between the Anatolia and Eurasia plates (Fig. 1). The fault system is characterized by dextral motion with an average slip rate of 20-30 mm/year (e.g., McClusky et al. 2000; Le Pichon et al. 2001), and it is composed of several segments (Barka and Kadinsky-Cade 1988). The eastern and central parts of the NAF consist of a single strand, but it branches into several strands west of the Sea of Marmara (SOM), which is a pull-apart basin that has formed along the NAF (Armijo et al. 1999, 2002, 2005). The fault system then extends westward into the Aegean Sea (AS) (e.g., Barka and Kadinsky-Cade 1988). The stress field along the fault system is characterized by transpression

\footnotetext{
* Correspondence: mnakano@jamstec.go.jp

'Japan Agency for Marine-Earth Science and Technology, Yokohama, Japan Full list of author information is available at the end of the article
}

around the SOM and by transtension beneath the AS (Mascle and Martin 1990; Kiratzi 2002).

Historical investigations of major earthquakes along the NAF have revealed that in the twentieth century, ruptures migrated westward after the 1939 Erzincan earthquake in eastern Turkey (Barka and Kadinsky-Cade 1988; Barka 1996). The 1999 İzmit (Mw 7.6) and Düzce $(M w 7.2)$ earthquakes occurred along the NAF just east of the SOM. West of the SOM, the Ganos fault ruptured in 1912. Beneath the AS, moderate earthquakes have occurred repeatedly in recent years. In 2003 an $M w 5.7$ earthquake occurred at the western end of the Ganos fault (Karabulut et al. 2006). In 2013, an $M w 5.8$ earthquake occurred south of Lemnos Island, south of the main NAF (Kiratzi and Svigkas 2013). Most recently, the 2014 Aegean Sea earthquake ( $M w$ 6.9, Global Centroid Moment Tensor Project, Dziewonski et al. 1981; Ekström et al. 2012) occurred west of the Ganos fault (Evangelidis 2015). The most recent activity beneath the SOM 


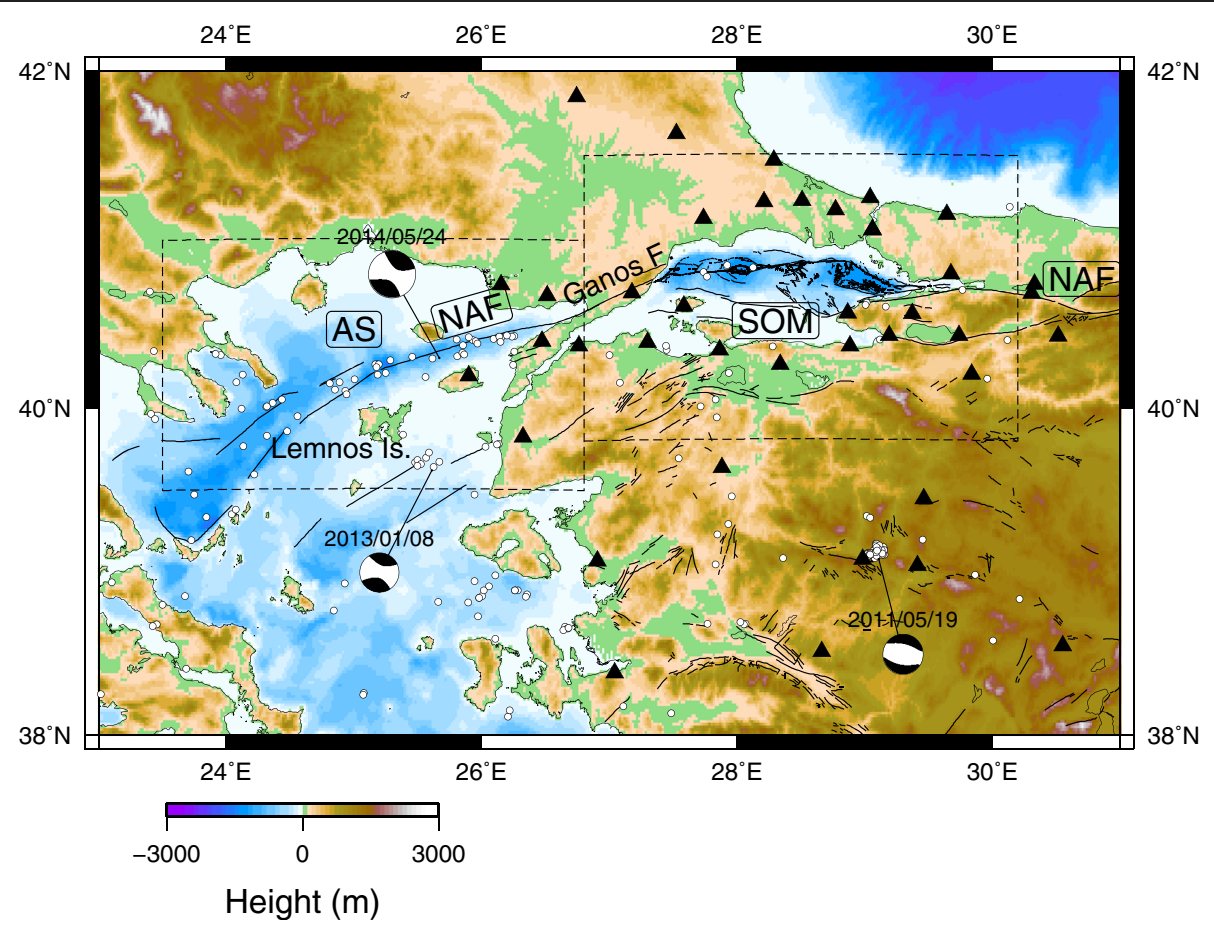

Fig. 1 Map showing the targeted areas in this study and the distribution of broad-band seismic stations in Turkey. Black triangles indicate the locations of seismic stations. White circles indicate distribution of earthquakes with magnitude larger than 4 that occurred between 2008 and 2014. CMT solutions of major earthquakes obtained by the GlobalCMT project are also displayed. Dashed rectangles enclose the target areas shown in Figs. 7 and 8. NAF, North Anatolian Fault; AS, Aegean Sea; SOM, Sea of Marmara

comparable to these large shocks, however, occurred in 1766 (Ambraseys and Jackson 2000; Meghraoui et al. 2012). Thus, there is a seismic gap beneath the SOM, and devastating earthquakes are anticipated in this region in the near future.

Because the seismic gap is beneath the sea, studies of the fault system geometry around the SOM have depended mostly on bathymetric surveys (e.g., Armijo et al. 2005). However, precise hypocenter determinations made using ocean-bottom seismometers (OBSs) also provide detailed information about fault geometries and activities (e.g., Sato et al. 2004; Yamamoto et al. 2015), and studies of earthquake focal mechanisms have also revealed fault geometries and stress fields around the SOM (Kiratzi 2002; Pinar et al. 2003; Sato et al. 2004; Örgülü 2011). Hébert et al. (2005) used information about the fault geometry of the NAF beneath the SOM to investigate the tsunami potential around the city of Istanbul, because damaging tsunamis have been triggered by historical earthquakes beneath the SOM. Detailed investigations of the tectonic background and fault geometries in this region will improve futureearthquake scenarios and be helpful for disaster mitigation (e.g., Hori et al. 2015).

Descriptions of individual fault segments are also important: Although the Coulomb stress on faults is released by earthquakes, the stress at segment boundaries increases both interseismically and coseismically, and fault ruptures tend to initiate there (Nakano et al. 2010). Detailed investigations of coseismic rupture during the 1999 İzmit earthquake revealed that rupture initiated at the boundary between the Sapanca and Gölcük segments of the NAF (Yagi and Kikuchi 2000; Delouis et al. 2002; Sekiguchi and Iwata 2002). It then propagated along both fault segments, resulting in a single large event. The epicenters of historical ruptures along the NAF are also located mainly at segment boundaries (Dewey 1976; Barka 1996). Initiation of earthquake ruptures at segment boundaries is also supported by numerical simulations (e.g., Duan and Oglesby 2006; Nakano et al. 2010). Therefore, the development of scenarios of future disastrous earthquakes requires detailed descriptions of fault segment boundaries along the NAF.

In order to reduce damages from earthquakes and tsunamis in the Marmara region, the Japan-Turkey joint project of "Earthquake and Tsunami Disaster Mitigation in the Marmara Region and Disaster Education in Turkey (MarDiM)" has started in 2013. This project has following objectives: 1. Development of earthquake source model based on detailed investigations of seismotectonic activities. 2. Construction of earthquake and tsunami scenarios using earthquake cycle simulations. 3 . 
Evaluations of earthquake and tsunami damages. 4. Education for disaster mitigation in Turkey. This project includes development of a rapid centroid moment tensor (CMT) determination system for early earthquake and tsunami responses. CMT distribution of background seismicity also can be used to investigate the tectonic setting in the target area.

In this study, we determined the CMT solutions of recent earthquakes beneath the SOM and AS to reveal the fault geometry, segmentation, and tectonic background along these sections of the NAF and identified the locations of several segment boundaries.

\section{Methods}

To determine the CMT solutions of earthquakes along the NAF, we used data obtained by Turkey's regional network of broad-band seismometers (Guralp CMG-3T, CMG-3ESP, or CMG-3ESPC), operated by the Kandilli Observatory and Earthquake Research Institute, Boğaziçi University (KOERI) (Fig. 1). We analyzed earthquakes that occurred between 2008 and 2014. Seismic events with magnitude larger than 4 in the target areas (enclosed by dashed rectangles in Fig. 1) were selected from the KOERI earthquake catalogue.

We used the SWIFT system (Nakano et al. 2008) for the CMT determinations. In this system, waveform inversion is carried out in the frequency domain to reduce the computational time. A pure double-couple source mechanism is assumed in order to stabilize the solution in case of using data from a small number of seismic stations. The fault and slip orientation angles are searched by a grid search. In the first version of the SWIFT system (Nakano et al. 2008), these parameters were searched every $15^{\circ}$. In the present version, these parameters are searched by using an adaptive grid spacing, in which the search angle is gradually decreased to $1^{\circ}$, to obtain more precise fault parameters without increasing the computational cost (Bonita et al. 2015; Punongbayan et al. 2015). By fitting synthetic waveforms to the observed ones in each frequency, we obtain the best-fitting fault parameters and the location of the source centroid. The normalized residual $R$ between observed and synthesized seismograms is given by

$$
R=\frac{\sum_{i=1}^{N_{t}} \sum_{k=1}^{N_{f}}\left|\tilde{u}_{i}^{o b s}\left(\omega_{k}\right)-\tilde{u}_{i}^{s y n}\left(\omega_{k}\right)\right|^{2}}{\sum_{i=1}^{N_{t}} \sum_{k=1}^{N_{f}}\left|\tilde{u}_{i}^{o b s}\left(\omega_{k}\right)\right|^{2}}
$$

where $\omega_{k}$ is the angular frequency, $\tilde{u}_{i}^{o b s}\left(\omega_{k}\right)$ and $\tilde{u}_{i}^{s y n}\left(\omega_{k}\right)$ are the Fourier transforms of the observed and synthetic displacement seismograms of $i$ th trace, and $N_{t}$ and $N_{f}$ are the number of waveform traces and number of frequency components used for the inversion, respectively. The synthetic waveforms and source-time functions are obtained by inverse Fourier transform of the estimated parameters in the frequency domain. Because band-passed waveforms are used for the inversion, the resulting moment function is a band-passed form. Accordingly, a deconvolved form of the moment function is reconstructed to obtain the source-time function from which we estimate the seismic moment (see Nakano et al. 2008 for details).

For the determinations of CMT solutions, the seismograms are corrected for the seismometer response, band-pass filtered between 20 and $50 \mathrm{~s}$, and integrated with respect to time to obtain displacement seismograms. Waveforms were decimated to a sampling interval of $2 \mathrm{~s}$. We used a total data length of $512 \mathrm{~s}$ (256 data points in each channel) for the inversion. Starting from the KOERI hypocenter, the best-fit source location is searched with a horizontal spacing of $0.1^{\circ}$ of latitude and longitude and a $5 \mathrm{~km}$ vertical (depth) spacing. For the computations of the Green's functions, we tried local velocity models in this area obtained by Karabulut et al. (2002), Karabulut et al. (2006), Gurbuz et al. (2000), as well as the standard Earth model ak135 (Kennet et al. 1995) to obtain one suitable for the CMT determinations.

For the analysis of each event, we visually checked the observed seismograms and selected those with good data quality. Several events, including the 2013 event beneath the AS (Mw 5.7), were not analyzed because of incomplete data due to temporary difficulties with the data recording system. For most events, more than 20 waveforms were used for the inversion. Waveforms from the horizontal components were weighted by 0.1 times compared with the vertical component at the same station because of their relatively larger amplitude and lower signal-to-noise ratio. The initial waveform inversion was carried out using the set of visually selected waveforms. We computed the cross-correlation coefficient (CC) between the observed and synthetic waveforms for the obtained fault and slip orientation parameters at the best-fitting source location of the initial search. To remove waveform traces strongly affected by noise, those with CCs smaller than 0.5 were removed from the dataset, and then we computed the inversion again using the remaining set of waveforms. We repeated this process until the CCs of all waveform traces were larger than 0.5 .

\section{Results}

\section{Velocity model}

We first investigated the velocity model for the computations of the Green's functions suitable for CMT determinations. We assumed velocity models obtained by Gurbuz et al. (2000), Karabulut et al. (2002), and Karabulut et al. (2006), which are one-dimensional velocity models in the 
crust obtained for the hypocenter determinations in this region. We also tried the standard Earth model ak135 (Kennet et al. 1995). In the model of Gurbuz et al. (2000) and Karabulut et al. (2006), we assumed $V p / V s=1.73$ (Fig. 2), where $V p$ and $V s$ are the $\mathrm{P}$ - and $\mathrm{S}$-waves velocities. The density was computed from $V p$ by using the empirical relationship of the Nafe-Drake curve (Brocher 2005). Since the velocity models of Gurbuz et al. (2000), Karabulut et al. (2002), and Karabulut et al. (2006) define the velocity structures above the crust, we used the model of ak135 in the mantle. The Green's functions are synthesized by using the discrete-wavenumber method (e.g., Bouchon 1979).

Waveform inversion is carried out for all the events using the same set of observed seismograms using the Green's functions computed for each structure model. Figure 3 compares cumulative frequency of the residual $R$. The average of residual $R$ for all events were 0.209, 0.203, 0.231 , and 0.269 for the models of ak135, Karabulut et al. (2002), Karabulut et al. (2006), and Gurbuz et al. (2000), respectively. The model of Karabulut et al. (2002) gave the smallest residual, although the difference from ak135 was very small. We used the velocity model of Karabulut et al. (2002) in the following CMT analysis.

\section{The 2014 Aegean Sea earthquake}

The 2014 Aegean Sea earthquake ( $M w 6$ 6.9) was the largest one included in our analysis and the most important for the investigations of the tectonic regime in the AS target area. Because of the earthquake's large magnitude, the observed seismograms at stations close to the source were clipped. Data from most of distant stations were incomplete due to temporary difficulties with the data recording system. Accordingly, we could use only four vertical waveforms from stations AYDB,

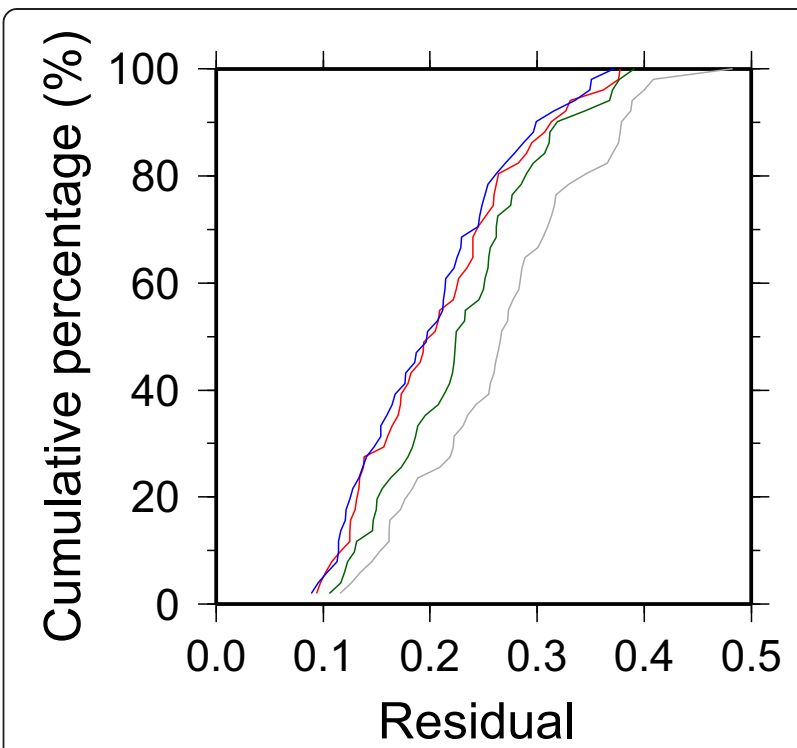

Fig. 3 Cumulative frequency of the residual $R$ of the waveform inversion. Red, blue, green and gray lines indicate the velocity models of ak135 (Kennet et al. 1995), Karabulut et al. (2002), Karabulut et al. (2006), and Gurbuz et al. (2000)

YLV, TVSB, and BODT (Fig. 4a) in the KOERI seismic network. Use of data from Greek seismic network would improve the azimuthal coverage of stations, but data from most broad-band stations were clipped or incomplete as the Turkey network. After checking data quality, we added a vertical component seismogram from station APE for the inversion of this event. Because the event occurred outside of the observation network, and all the stations are located east to south of the hypocenter, the azimuthal gap of the station coverage was $270^{\circ}$. Generally, when a small number of waveforms are used with a large azimuthal gap, the
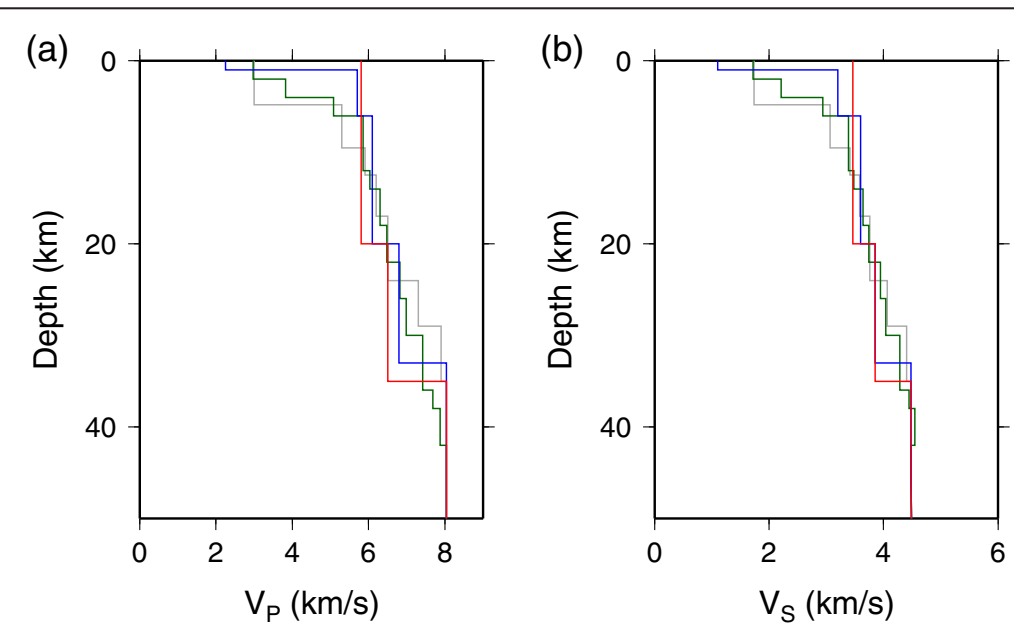

Fig. 2 Seismic velocity structure used for the computations of the Green's functions. a P-wave velocity. b S-wave velocity. Red, blue, green, and gray lines indicate the velocity models of ak135 (Kennet et al. 1995), Karabulut et al. (2002), Karabulut et al. (2006), and Gurbuz et al. (2000) 

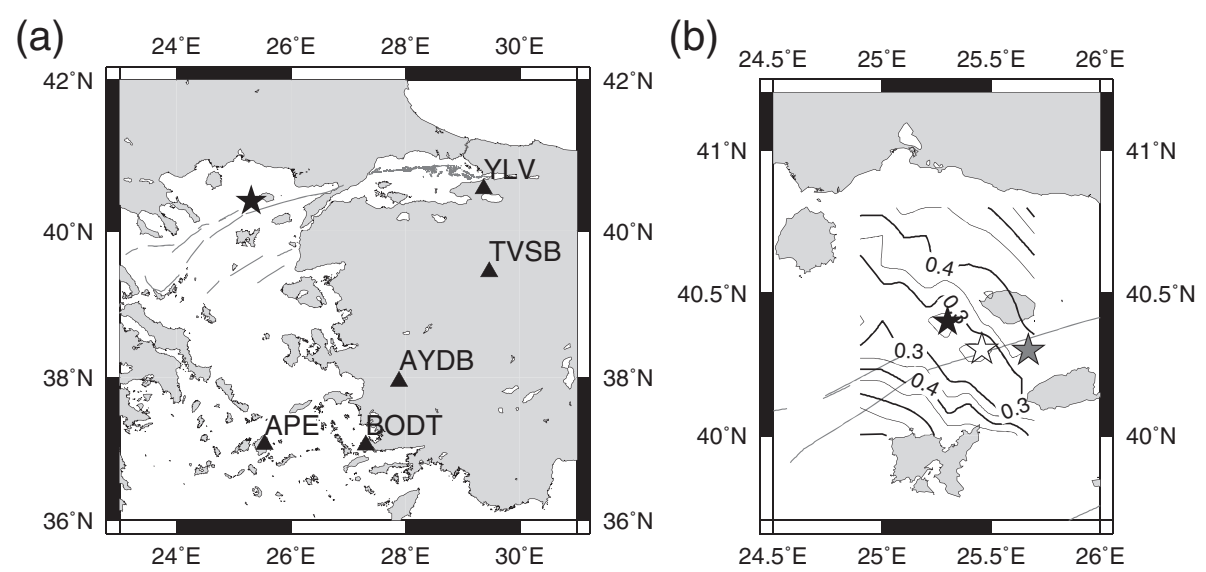

Fig. 4 Map showing the source location of the 2014 Aegean Sea earthquake. a Stations used for the moment tensor inversion. Filled star indicate the obtained source centroid location. Gray lines indicate the fault traces. b Map showing contour lines representing the spatial distribution of the residuals of our waveform inversion. White and gray stars indicate the source locations from the KOERI catalogue and the Global CMT project, respectively

source inversion yields an unstable solution. The SWIFT system assumes a pure double-couple source to stabilize the inversion in such cases. Also, the signal-tonoise ratio of the long-period components was high for this event because of its large magnitude. In the numerical investigations of Nakano et al. (2008) using the SWIFT system, three component waveforms from three stations are sufficient to obtain accurate CMT solution even a large azimuthal gap exists. Our analysis, however, depends only on vertical components, and we carefully evaluate the accuracy of the CMT solution for this event.

We obtained the source centroid at $40.4^{\circ} \mathrm{N}, 25.3^{\circ} \mathrm{E}$, and $15-\mathrm{km}$ depth, northwest of the KOERI hypocenter location, off the topographic depression in the AS (Fig. 4b). The residual contour of waveform inversion (Fig. 4b) elongated in the NW-SE direction, indicating weak resolution of the source centroid location in this direction due to the large azimuthal gap of stations and use of only vertical component data. The focal mechanism represented strike-slip faulting similar to that obtained by the Global CMT project, which is consistent with the motion of the NAF (Fig. 5). The estimated moment function (Fig. 6a) indicated a seismic moment of $3.75 \times 10^{19} \mathrm{Nm}$ and a moment magnitude of 7.0, slightly larger than the estimated value of Global CMT. The moment function consisted of several distinct subevents (Fig. 6b), which we discuss later (see "Discussion"). The synthetic waveforms reproduced the observed waveforms well, with a normalized residual $R$ of 0.22 (Fig. 6c).

Because only vertical component seismograms from five stations were used for the inversion of this event and the azimuthal gap was $270^{\circ}$, we checked the stability of the solution by plotting the variations of nodal planes (a)

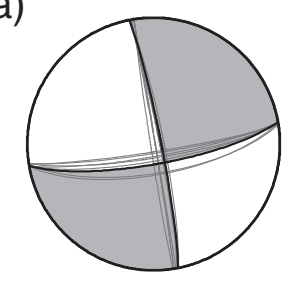

(c)

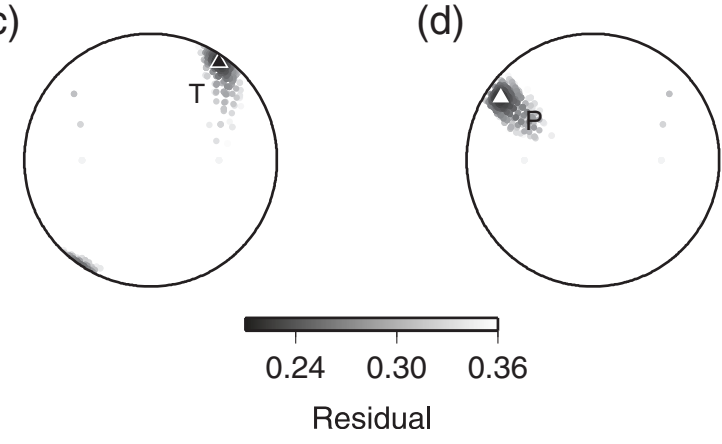

Fig. 5 Diagrams showing the stability of the CMT inversion of the 2014 Aegean Sea earthquake. a Obtained focal mechanism and variations of the nodal planes obtained at locations surrounding the best-fitting source centroid. Those obtained at the eight surrounding grids $\left(0.1^{\circ}\right.$ difference) in the horizontal directions next to the best-fit location are plotted together with the best-fit solution. b Focal mechanism obtained by the GlobalCMT project, plotted with the nodal planes of best double-couple. $\mathbf{c}$, $\mathbf{d}$ The residual distributions with respect to the directions of the $\mathrm{T}$ - and $\mathrm{P}$-axes, respectively, plotted on the focal sphere at the best-fit source location. The filled and open triangles indicate the direction of the best-fitting $\mathrm{T}$ - and P-axes 
(a)

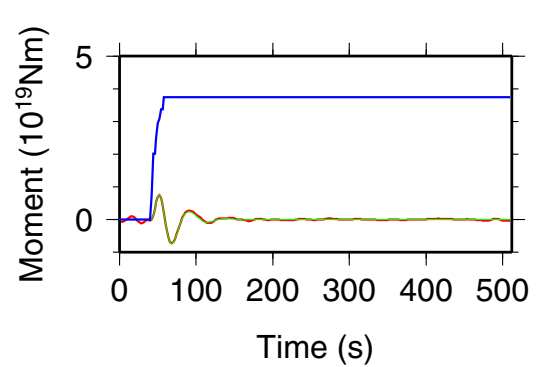

(c)
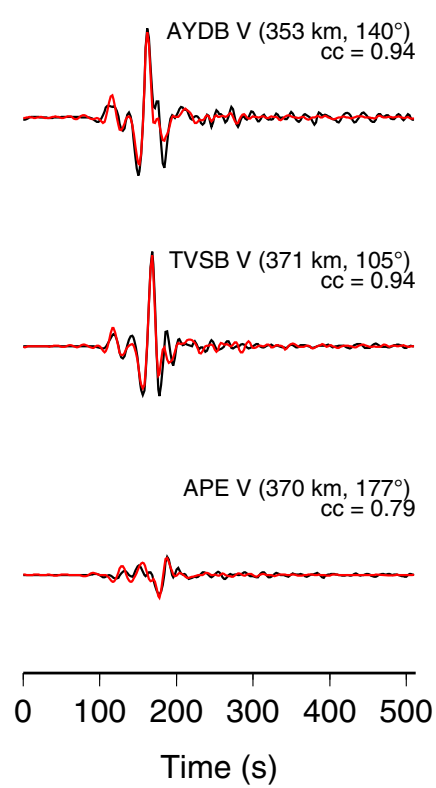

(b)

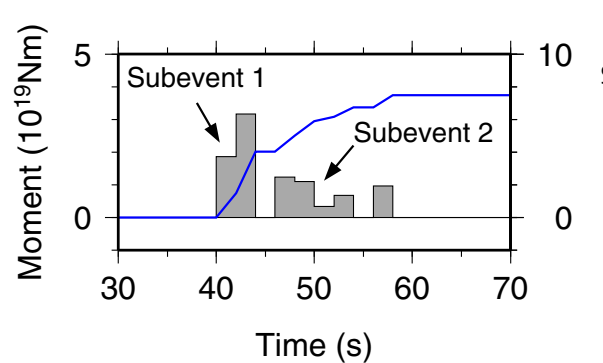

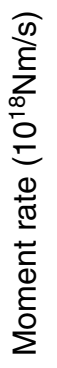
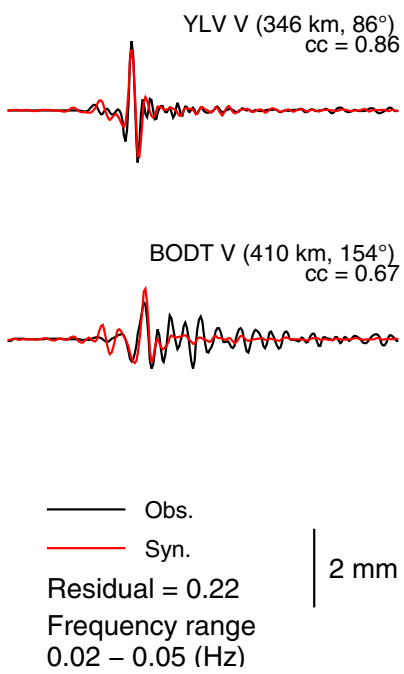

Fig. 6 Source-time function and waveform match for the 2014 Aegean Sea earthquake. a Blue line: reconstructed source-time function. Red line: bandpassed source-time function obtained by waveform inversion. Green line: band-passed form of the reconstructed source-time function (blue line), which is fitted to the red line. $\mathbf{b}$ Magnified source-time function. Gray bars indicate the moment-rate function corresponding to the moment function (right axis). c Waveform match obtained from the waveform inversion. The black and red lines represent observed and synthesized waveforms, respectively. The station code, component of motion, distance from the source centroid, and azimuth are indicated above each seismogram. The cross-correlation coefficient (cc) between the observed and synthesized seismograms in the inversion is indicated beneath each station code

obtained in the grids surrounding the best-fitting source location (Fig. 5a). The nodal planes were close to the one obtained at the best-fitting source. Figure $5 \mathrm{c}$, d show the residual distribution with respect to the directions of the $\mathrm{P}$ - and $\mathrm{T}$-axes, respectively, obtained at the bestfitting source location plotted on the focal sphere. The small variations indicate that our analysis stably estimated the focal mechanism. The stability of the solution despite the small number of waveforms was attributable to the good quality of the waveforms and double-couple focal mechanism assumption in the SWIFT system.

\section{CMT distributions beneath the Aegean Sea}

Figure 7 shows the distribution of CMT solutions obtained beneath the AS in this study. Although the target area was outside of the observation network, CMT solutions were stably obtained. Most of the source centroids were at depths of 5 to $10 \mathrm{~km}$. The difference between the centroid and epicenter locations was mostly smaller than $0.1^{\circ}$ in eastern AS. The difference was larger in the western AS with $0.2^{\circ}-0.4^{\circ}$ because of the large azimuthal gap, indicating relatively weak resolution in the source centroid location. Most focal mechanisms represented strike-slip or normal faults, both with $\mathrm{T}$-axes oriented NE-SW, reflecting the regional stress field. This result is consistent with the transtensional tectonic regime in this region (Mascle and Martin 1990; Kiratzi 2002).

The most intensive activity during the analysis period was found along the NAF east of the 2014 earthquake source. This activity includes aftershocks of the 2014 event, but the activity earlier than the 2014 event likely 


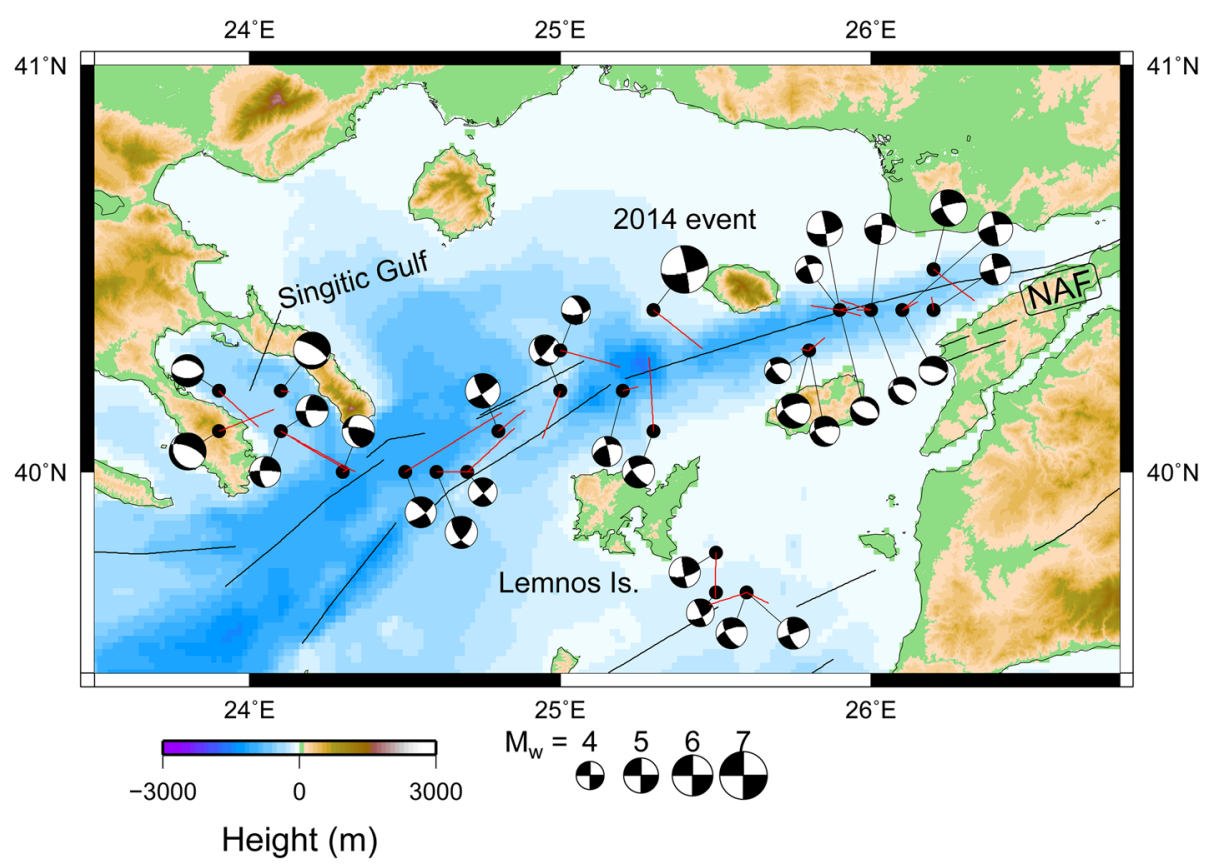

Fig. 7 Distribution of CMT solutions around the Aegean Sea. Black circles indicate the locations of the source centroids. Red bars connect the source centroid locations with the corresponding hypocenters

relates to the 2003 earthquake (Mw 5.7) on the Ganos fault (Fig. 1), because the aftershock distribution of that event largely overlaps this area of recent seismic activity (Karabulut et al. 2006). Although Karabulut et al. (2006) found only strike-slip events in their analysis, we identified normal fault events both before and after the 2014 event. These normal fault events, which are indicative of a transtensional stress regime in the AS, would be related to the formation of the topographic depression along the NAF.

West of the 2014 event source along the NAF, most events displayed strike-slip mechanisms. The T-axes of these events were oriented $\mathrm{N}-\mathrm{S}$, slightly rotated counterclockwise compared to those of the eastern events. This result is consistent with the change in the strike of the NAF west of $25^{\circ}$ E. Further west, activity was most intensive beneath the Singitic Gulf, Greece. Earthquakes were aligned NW-SE, corresponding to the strike of a conjugate fault of the main NAF (not mapped), although the source centroid location was not well resolved in this direction. In this activity, the magnitudes of normal fault earthquakes were larger than those of strike-slip events, an indication that tensional stress is dominant in this region.

Other branch faults are thought to run south of the main NAF and Lemnos Island around the source of the 2013 event (e.g., Kiratzi and Svigkas, 2013). Earthquake alignment was not clear in our analysis. Kiratzi and Svigkas (2013) reported that the 2013 event occurred on an unmapped fault. Further investigations are necessary to clarify the fault distribution.

\section{CMT distributions beneath the Sea of Marmara}

Figure 8 displays the distribution of CMT solutions obtained around the SOM. These solutions were more stable than those obtained beneath the AS because the azimuthal coverage of the stations was much better. The difference between the source centroid and the epicenter was less than $0.1^{\circ}$ (grid spacing of our CMT analysis) for most events. The sources were at depths between 5 and $20 \mathrm{~km}$. Along the main NAF beneath the SOM, we obtained CMT solutions for only four events due to the low seismic activity (Fig. 1). These earthquakes occurred in the western SOM beneath the Western High (WH) and Central Basin (CB). Their CMT solutions were characterized by strike-slip motion, as expected from the tectonic setting, except for one normal fault event beneath the WH. We discuss the tectonic background of the normal fault event later (see "Discussion").

East of the CB is a seismic gap without any CMT solutions beneath the SOM. West of the SOM in the mapped area, we obtained only one CMT solution, showing strike-slip faulting, off the trace of the main NAF. Along the Ganos fault, where three major earthquakes occurred in 1912, there is a seismic gap in the recent seismic activity (Karabulut et al. 2006) and we did not obtain any CMT solutions. 


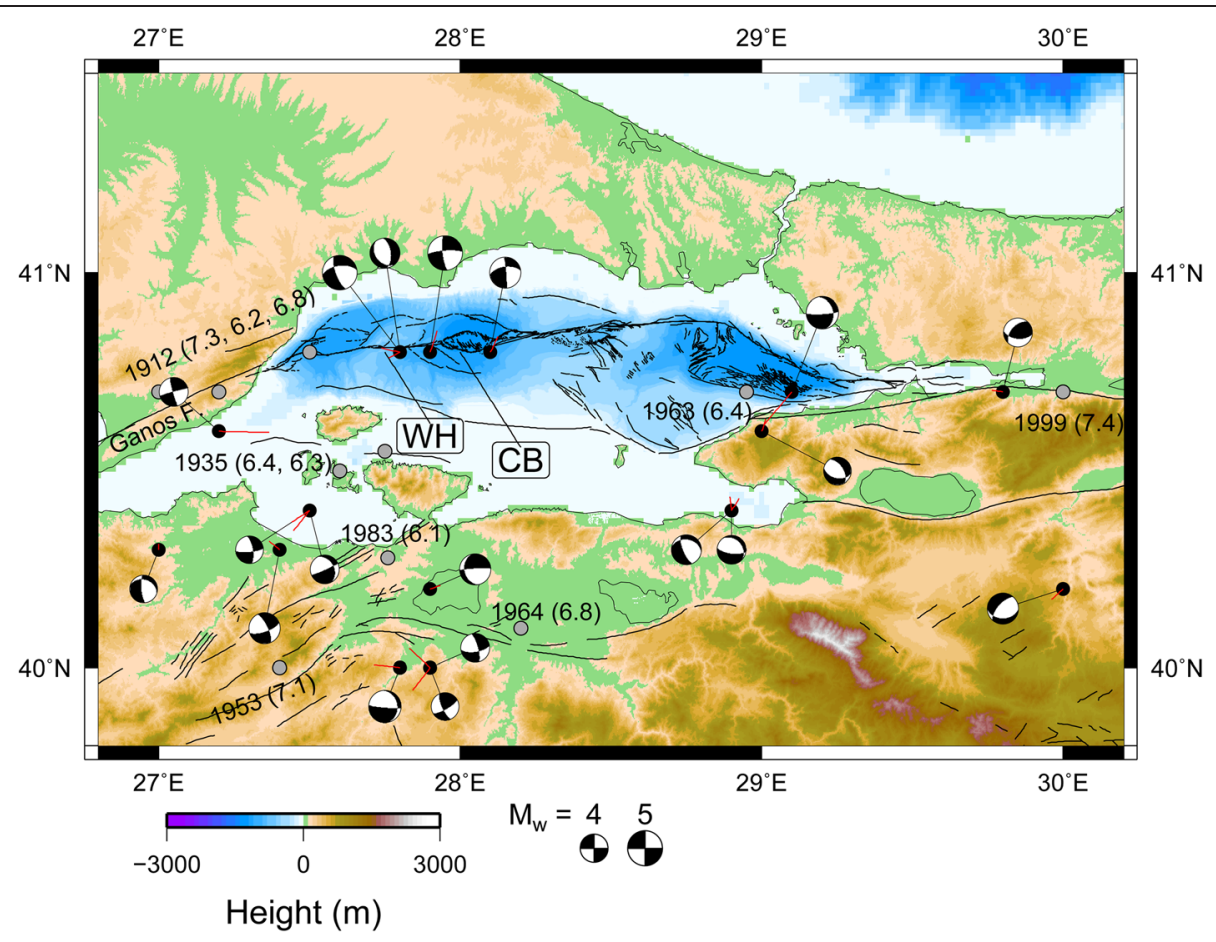

Fig. 8 Distribution of CMT solutions around the Sea of Marmara. Filled circles indicate the locations of source centroids. Gray circles indicate the locations of major earthquakes in the twentieth century, labeled with occurrence date and, in parentheses, earthquake magnitudes (after Ambraseys and Jackson, 2000). Red bars connect the source centroid locations with the corresponding hypocenters. WH, Western High; CB, Central Basin

To the southwest of the SOM, several moderate to large earthquakes occurred in the twentieth century (Ambraseys and Jackson 2000). A number of active branch faults of the NAF have been mapped in this region (Barka and Kadinsky-Cade 1988), but the earthquake distribution is rather scattered and off the fault traces (Fig. 8). The focal mechanisms were mostly characterized by strike-slip motion with a normal fault component to some degree. In each case, one of the nodal planes was parallel to the strike of the active faults, and we consider the present activity to reflect the crustal motion that caused these major earthquakes. The obtained distribution of focal mechanisms is mostly consistent with the tectonics and stress field in this region as reported by previous studies (Kiratzi 2002; Pinar et al. 2003; Sato et al. 2004; Örgülü 2011).

South of the SOM at around $29^{\circ} \mathrm{E}$, we obtained CMT solutions for several normal fault events with $\mathrm{T}$-axes oriented NE-SW. These events would be related to the crustal opening that formed the SOM (Armijo et al. 1999, 2002).

\section{Discussion}

Our CMT inversion result for the 2014 Aegean Sea earthquake revealed a source-time function with several subevents, with durations of about 4 and $8 \mathrm{~s}$ for the first and second ones, respectively (Fig. 6b). This result is consistent with the back-projection source imaging of this earthquake conducted by Evangelidis (2015). His analysis revealed that the rupture of this event first propagated westward from the hypocenter, and the eastern segment ruptured after that, also initiating from the hypocenter (Evangelidis 2015, his Fig. 4). The westward and eastward ruptures would correspond to the first and second subevents, respectively, obtained in our analysis. Although ruptures propagated both east and west from the hypocenter, this event was not a bilateral rupture; rather, it consisted of two distinct unilateral ruptures. How can such ruptures occur? Nakano et al. (2010) have already reproduced the signature of dual ruptures in a simulation of an earthquake doublet that occurred at a segment boundary of the Sumatran fault, Indonesia. This fault system is also characterized by right-lateral motion on strike-slip faults, and it is divided into about 20 major fault segments (Sieh and Natawidjaja 2000). By setting the initial stress to a sufficiently high value, close to the shear strength, the dynamic stress changes caused by the rupture of one fault segment triggers rupture on the secondary fault after a delay (Nakano et al. 2010, their Figure ten). The existence of a mechanical barrier (in the case of their study, a segment boundary) 
prevents the simultaneous rupture of the two segments. These observations and simulations imply that there exists a mechanical barrier, possibly a segment boundary of the NAF, at the hypocenter of the 2014 Aegean Sea earthquake, although this geometry has not been mapped yet because the fault trace is beneath the sea. Nakano et al. (2010) inferred that Coulomb stress increases both interseismically and coseismically at a segment boundary and that ruptures tend to initiate there. This model is also consistent with the observation of the 2014 Aegean Sea earthquake if we assume that a segment boundary exists at the hypocenter.

Yagi and Kikuchi (2000) similarly described two unilateral ruptures in a study of fault rupture propagation during the 1999 İzmit earthquake; rupture of the eastern segment initiated about $7 \mathrm{~s}$ after the initiation of rupture of the western segment. Other studies of the same event, however, reported a bilateral rupture (Delouis et al. 2002; Sekiguchi and Iwata 2002). If the model of two unilateral ruptures is applicable to other recent earthquakes along the NAF, it would imply that the stress level along the faults had been high and close to their shear strength. Detailed investigation of the state of stress in this region is therefore a matter of great urgency, and earthquake rupture simulation scenarios for future disastrous events (e.g., Hori et al. 2015) should include a model that can reproduce two unilateral ruptures initiating at a segment boundary.

Beneath the SOM, we found a normal fault event around the WH between strike-slip events along the NAF (Fig. 5). The T-axis of this normal fault event was almost parallel to the strike of the NAF. Armijo et al. (2005) identified a small pull-apart basin developing at this location. The presence of a normal fault is consistent with a tensional stress field caused by the crustal opening due to the pull-apart. Although no normal fault earthquakes have yet been reported around the WH (Kiratzi 2002; Pinar et al. 2003; Sato et al. 2004; Örgülü 2011), Yamamoto et al. (2015) identified several earthquakes that are consistent with pull-apart activity by using intensive OBS observations. They also identified strike-slip earthquakes in this region. Örgülü (2011) found similar activity beneath the $\mathrm{CB}$; normal fault earthquakes were observed between strike-slip events along the NAF where a major pull-apart basin is developing. Taken together, these results indicate that a pullapart basin is developing beneath the WH and that it marks a segment boundary of the NAF.

Armijo et al. (2005) pointed out that the 1912 Ganos earthquakes ruptured fault segments around the WH and terminated beneath the $\mathrm{CB}$. Thus, the seismic potential along this part of the SOM should be low compared to that in the seismic gap beneath the central to eastern SOM. Nevertheless, Yamamoto et al. (2015) reported intensive, but intermittent, seismic activity beneath WH. We attribute this activity to stress accumulation and release at an asperity at the fault segment boundary, which implies some seismic potential there.

\section{Conclusions}

We obtained distributions of centroid moment tensor solutions around the Aegean Sea and Sea of Marmara by using data from the regional broad-band seismic network in Turkey. The source-time function obtained for the 2014 Aegean Sea earthquake indicated that this event consisted of at least two subevents. The first event ruptured the western fault segment, and the second event ruptured the eastern fault segment. This result indicates the existence of a segment boundary at the hypocenter. We also found a normal fault earthquake between strike-slip fault events beneath the western Sea of Marmara, which also indicates the existence of a segment boundary of the North Anatolian fault at the source location. Detailed investigations of earthquake distributions and focal mechanisms are needed to reveal the fault geometry and state of stress along the fault system. Because the occurrence and slip distributions of major earthquakes are strongly affected by fault length and geometry, mapping the fault segments would provide valuable information that would be useful for developing scenarios for future earthquakes. Seismic activities around such structures should be monitored to evaluate their seismic potential and to develop rupture propagation scenarios for future devastating earthquakes.

\section{Abbreviations}

AS: Aegean Sea; CC: Cross-correlation coefficient; MarDIM: Marmara Disaster Mitigation; NAF: North Anatolian fault; OBS: Ocean-bottom seismometer; SOM: Sea of Marmara; WH: Western High in the Sea of Marmara.

\section{Competing interests}

The authors declare that they have no competing interests.

\section{Authors' contributions}

MN performed the entire analysis and wrote the manuscript. SC processed the data. DK managed the seismic observation network. All authors approved the manuscript.

\section{Acknowledgements}

We used global topographic and bathymetric data of the Shuttle Radar Topography Mission (SRTM) and ETOPO1 for plotting the maps in Figs. 1, 7, and 8. In Fig. 8, we also used detailed bathymetric data of the Sea of Marmara supplied by Armijo et al. (2005). Fault traces shown in Figs. 1, 4, 7, and 8 are after Le Pichon et al. (2001) and Armijo et al. (2005). Data from Greek seismic network was downloaded from Geofon (geofon.gfzpotsdam.de). We thank Dr. Y. Yamamoto, T. Hori, and R. Ando for fruitful discussions. This study is part of the "Earthquake and Tsunami Disaster Mitigation in the Marmara Region and Disaster Education in Turkey (MarDiM)" project, financially supported by the Japan International Cooperation Agency (JICA), the Japan Science and Technology Agency (JST), and the Ministry of Development in Turkey. All figures were drawn by using Generic Mapping Tools (Wessel and Smith 1998). 


\section{Author details}

${ }^{1} J a p a n$ Agency for Marine-Earth Science and Technology, Yokohama, Japan. ${ }^{2}$ Kandilli Observatory and Earthquake Research Institute, Boğaziçi University, Istanbul, Turkey.

Received: 11 June 2015 Accepted: 16 September 2015 Published online: 28 September 2015

\section{References}

Ambraseys NN, Jackson JA (2000) Seismicity of the Sea of Marmara (Turkey) since 1500. Geophys J Int 141:F1-F6

Armijo R, Meyer B, Hubert A, Barka A (1999) Westward propagation of the North Anatolian fault into the northern Aegean: timing and kinematics. Geology 27:267-270. doi:10.1130/0091-7613(1999)027<0267:WPOTNA>2.3.CO;2

Armijo R, Meyer B, Navarro S, King G, Barka A (2002) Asymmetric slip partitioning in the Sea of Marmara pull-apart: a clue to propagation processes of the North Anatolian Fault? Terra Nova 14:80-86

Armijo R, Pondrad N, Meyer B, Uçarkus G, de Lépinary BM, Malavielle J, Dominguez S, Gustcher M-A, Schmidt S, Beck C, Çagatay N, Çakir Z, Imren C, Eris K, Natalin B, Özalabey S, Tolun L, Lefévre I, Seeber L, Gasperini L, Rangin C, Emre O, Sarikavak K (2005) Submarine fault scarps in the Sea of Marmara pull-apart (North Anatolian Fault): Implications for seismic hazard in Istanbul. Geochem Geophys Geosyst 6:Q06009. doi:10.1029/2004GC000896

Barka A (1996) Slip distribution along the North Anatolian Fault associated with the large earthquakes of the period 1939 to 1967. Bull Seismo Soc Am 86:1238-1254

Barka AA, Kadinsky-Cade K (1988) Strike-slip fault geometry in Turkey and its influence on earthquake activity. Tectonics 7:663-684

Bonita JD, Kumagai H, Nakano M (2015) Regional Moment Tensor Analysis in the Philippines: CMT Solutions in 2012-2013. J Disaster Res 10:18-24

Bouchon M (1979) Discrete wave number representation of elastic wave fields in three-space dimensions. J. Geophys Res 84:3609-3614

Brocher TM (2005) Empirical relations between elastic wavespeeds and density in the Earth's crust. Bull Seism Soc Am 95:2081-2092. doi:10.1785/0120050077

Delouis B, Giardini D, Lundgren P, Salichon J (2002) Joint Inversion of InSAR, GPS, Teleseismic, and Strong-Motion Data for the Spatial and Temporal Distribution of Earthquake Slip: Application to the 1999 Izmit Mainshock. Bull Seism Soc Am 92:278-299

Dewey JW (1976) Seismicity of northern Anatolia. Bull seism Soc Am 66:843-868

Duan B, Oglesby DD (2006) Heterogeneous fault stresses from previous earthquakes and the effect on dynamics of parallel strike-slip faults. J Geophys Res 111:B05309. doi:10.1029/2005JB004138

Dziewonski AM, Chou TA, Woodhouse JH (1981) Determination of earthquake source parameters from waveform data for studies of global and regional seismicity. J Geophys Res 86:2825-2852. doi:10.1029/JB086iB04p02825

Ekström G, Nettles M, Dziewonski AM (2012) The global CMT project 2004-2010: Centroid-moment tensors for 13,017 earthquakes. Phys Earth Planet Inter 200-201:1-9. doi:10.1016/j.pepi.2012.04.002

Evangelidis CP (2015) Imaging supershear rupture for the 2014 Mw 6.9 Northern Aegean earthquake by backprojection of strong motion waveforms. Geophys Res Lett 42:307-315. doi:10.1002/2014GL062513

Gurbuz C, Aktar M, Eyidogan H, Cisternas A, Haessler H, Barka A, Ergin M, Türkelli N, Polat O, Üçer SB, Kuleli S, Baris S, Kaypak B, Bekler T, Zor E, Bicmen F, Yoruk A (2000) The seismotectonics of the Marmara region (Turkey): results from a microseismic experiment. Tectonophysics 316:1-17

Hébert H, Schindelé F, Altinok Y, Alpar B, Gazioglu C (2005) Tsunami hazard in the Marmara Sea (Turkey): a numerical approach to discuss active faulting and impact on the Istanbul coastal areas. Mar Geol 215:23-43. doi:10.1016/j.margeo.2004.11.006

Hori T, Yalciner A, Ozel N, Kilic I, Miyazaki S, Hyodo M (2015) Earthquake generation cycles and tsunami simulations providing possible scenarios for Turkey (Marmara sea) and Japan (Nankai trough and Japan trench). Paper presented at 2015 Annual Meeting, EGU, Vienna

Karabulut H, Bouin MP, Bouchon M, Dietrich M, Cornou C, Aktar M (2002) The seismicity in the eastern Marmara Sea after the 17 August 1999 Izmit earthquake. Bull Seism Soc Am 92:387-393

Karabulut H, Roumelioti Z, Benetatos C, Mutlu AK, Özalaybey S, Aktar M, Kiratzi A (2006) A source study of the 6 July 2003 (Mw 5.7) earthquake sequence in the Gulf of Saros (Northern Aegean Sea): Seismological evidence for the western continuation of the Ganos fault. Tectonophysics 412:195-216. doi:10.1016/j.tecto.2005.09.009
Kennet BLN, Engdahl ER, Buland R (1995) Constraints on seismic velocities in the Earth from traveltimes. Geophys J Int 122:108-124

Kiratzi AA (2002) Stress tensor inversions along the westernmost North Anatolian Fault Zone and its continuation into the North Aegean Sea. Geophys J Int 151:360-376

Kiratzi AA, Svigkas N (2013) A study of the 8 January 2013 Mw5.8 earthquake sequence (Lemnos Island, East Aegean Sea). Tectonophysics 608:452-460. doi:10.1016/j.tecto.2013.09.002

Le Pichon X, Şengör AMC, Demirbağ E, Rangin C, İmren C, Armijo R, Görür N, Çağatay N, de Lepinay BM, Meyer B, Saatçılar R, Tok B (2001) The active main Marmara fault. Earth Planet Sci Lett 192:595-616

Mascle J, Martin L (1990) Shallow structure and recent evolution of the Aegean Sea: a synthesis based on continuous reflection profiles. Mar Geol 94:271-299

McClusky S, Balassanian S, Barka A, Demir C, Ergintasv S, Georgiev I, Gurkan O, Hamburger M, Hurst K, Kahle H, Kastens K, Kekelidze G, King R, Kotzev V, Lenk O, Mahmoud S, Mishin A, Nadariya M, Ouzounis A, Paradisssis D, Peter Y, Prilepin M, Reilinger R, Sanli I, Seeger H, Tealeb A, Toksoz MN, Veis G (2000) Global positioning system constraints on plate kinematics and dynamics in the Eastern Mediterranean and Caucasus. J Geophys Res 105:5695-5719

Meghraoui M, Aksoy ME, Akyüz HS, Ferry M, Dikbaş A, Altunel E (2012) Paleoseismology of the North Anatolian Fault at Güzelköy (Ganos segment, Turkey): size and recurrence time of earthquake ruptures west of the Sea of Marmara. Geochem Geophys Geosyst 13:Q04005. doi:10.1029/2011GC003960

Nakano M, Kumagai $\mathrm{H}$, Inoue H (2008) Waveform inversion in the frequency domain for the simultaneous determination of earthquake source mechanism and moment function. Geophys J Int 173:1000-1011. doi:10.1111/j.1365-246X.2008.03783.X

Nakano M, Kumagai H, Toda S, Ando R, Yamashina T, Inoue H, Sunarjo (2010) Source model of an earthquake doublet that occurred in a pull-apart basin along the Sumatran fault, Indonesia. Geophys J Int 181:141-153. doi:10.1111/j.1365-246X.2010.04511.X

Örgülü G (2011) Seismicity and source parameters for small-scale earthquakes along the splays of the North Anatolian Fault (NAF) in the Marmara Sea. Geophys J Int 184:385-404. doi:10.1111/j.1365-246X.2010.04844.X

Pinar A, Kuge K, Honkura Y (2003) Moment tensor inversion of recent small to moderate sized earthquakes: implications for seismic hazard and active tectonics beneath the Sea of Marmara. Geophys J Int 153:133-145

Punongbayan BJT, Kumagai H, Pulido N, Bonita JD, Nakano M, Yamashina T, Maeda Y, Inoue H, Melosantos AA, Figueroa MF, Narag IC, Solidum R Jr (2015) Development and operation of a regional moment tensor analysis system in the Philippines: contributions to the understanding of recent damaging earthquakes. J Disaster Res 10:25-34

Sato T, Kasahara J, Taymaz T, Ito M, Kamimura A, Hayakawa T, Tan O (2004) A study of microearthquake seismicity and focal mechanisms within the Sea of Marmara (NW Turkey) using ocean bottom seismometers (OBSs). Tectonophysics 391:303-314

Sekiguchi H, Iwata T (2002) Rupture process of the 1999 Kocaeli, Turkey, earthquake estimated from strong-motion waveforms. Bull Seism Soc Am 92:300-311

Sieh K, Natawidjaja D (2000) Neotectonics of the Sumatran fault, Indonesia. J Geophys Res 105:28295-28326

Wessel P, Smith WHF (1998) New version of the generic mapping tools released. EOS Trans AGU 76:329

Yagi Y, Kikuchi M (2000) Source rupture process of the Kocaeli, Turkey, earthquake of August 17, 1999, obtained by joint inversion of near-field data and teleseismic data. Geophys Res Lett 27:1969-1972

Yamamoto Y, Takahashi N, Citak S, Kalafat D, Pinar A, Gurbuz C, Kaneda Y (2015) Offshore seismicity in the western Marmara Sea, Turkey, revealed by ocean bottom observation. Earth Planet Space (in this special issue) 